Société d'histoire de la révolution de 1848 et des révolutions du XIXe siècle

49 | 2014

1814-1815. Expériences de la discontinuité

Marion FONTAINE, Frédéric MONIER et Christophe PROCHASSON [dir.], Une contre-histoire de la Troisième République

Paris, La Découverte, 2013, 402 p. ISBN : 978-2707174239. 26,50 euros.

Bruno Dumons

\title{
OpenEdition
}

Journals

Édition électronique

URL : http://journals.openedition.org/rh19/4779

DOI : $10.4000 /$ rh 19.4779

ISSN : $1777-5329$

Éditeur

La Société de 1848

Édition imprimée

Date de publication : 1 décembre 2014

Pagination : 227-228

ISSN : 1265-1354

Référence électronique

Bruno Dumons, "Marion FONTAINE, Frédéric MONIER et Christophe PROCHASSON [dir.], Une contrehistoire de la Troisième République », Revue d'histoire du XIXe siècle [En ligne], 49 | 2014, mis en ligne le 01 décembre 2014, consulté le 22 septembre 2020. URL : http://journals.openedition.org/rh19/4779 DOI : https://doi.org/10.4000/rh19.4779

Ce document a été généré automatiquement le 22 septembre 2020.

Tous droits réservés 


\section{Marion FONTAINE, Frédéric MONIER et Christophe PROCHASSON [dir.], Une contre-histoire de la Troisième République}

Paris, La Découverte, 2013, 402 p. ISBN : 978-2707174239. 26,50 euros.

\section{Bruno Dumons}

\section{RÉFÉRENCE}

Marion FONTAINE, Frédéric MONIER et Christophe PROCHASSON [dir.], Une contrehistoire de la Troisième République, Paris, La Découverte, 2013, 402 p. ISBN :

978-2707174239. 26,50 euros.

Après le monumental Dictionnaire critique de la République (2002), fallait-il une dizaine d'années plus tard une contre-histoire de la Troisième République (2013) ? Derrière cette question impertinente, avouons-le, il y a d'abord une légitime interrogation sur la pertinence d'un tel projet historiographique. Est-ce le contexte politique d'un retour de la gauche au pouvoir en 2012 qui l'aurait suscité ? Assurément non, même si les vagues historiographiques successives sur la République et la républicanisation de la société française ont souvent été contemporaines du retour de la gauche républicaine au pouvoir. À l'heure du triomphe de l'histoire sociale, le succès éditorial des livres classiques de Maurice Agulhon en a été un exemple ${ }^{1}$. Il a ensuite été question d'un "modèle républicain », caractéristique d'un moment, celui de la République troisième du nom, plus particulièrement d'une séquence qui s'étend entre les années 1880 à 1914. Il constituerait une sorte de Table de la Loi, de canon des Écritures, à partir desquelles se seraient sanctuarisées des institutions et des valeurs, diffusées par des symboles et des cultures ${ }^{2}$. En temps de crises politiques, il servirait également de remède, voire d'héritage, dans lequel puiseraient les différentes familles politiques républicaines. 
C'est précisément la validité intemporelle de ce modèle républicain qu'interrogent Marion Fontaine, Frédéric Monier et Christophe Prochasson, responsables de ce volume, avec la collaboration d'une vingtaine d'auteurs.

La méthode employée revêt deux volets : l'un consiste à s'attaquer aux "idées reçues » qui incarnent cette Troisième République, l'autre à démonter les « boîtes noires » de ce régime. Deux parties distinctes mais complémentaires qui structurent l'ouvrage. En premier lieu, les quatorze «idées reçues» recensées ici s'ordonnent autour des problématiques de pouvoir, de régulation sociale et d'exclusion. Si certaines d'entre elles demeurent des classiques (l'élection, l'armée, l'école, etc.), d'autres renouent avec des débats passionnés (le suffrage dit "universel», la République des ouvriers, la République coloniale, la République antireligieuse). Quelques-unes enfin s'appuient sur des renouvellements historiographiques récents (l'ordre républicain et le droit constitutionnel). Ici, les propos de Quentin Deluermoz reprennent à nouveaux frais les principes qui fondent l'acceptation de l'ordre dans la Troisième République tandis que la contribution du politiste Guillaume Sacriste apporte un éclairage neuf sur ces juristes républicains qui ont inscrit le droit positif dans les gênes de ce régime.

3 Le second volet sur les «boîtes noires » de la République cherche à donner un éclairage sur des héritages, des normes et processus qui ont fabriqué et pérennisé ce régime de la Troisième République. On y trouve des réflexions inédites. Ainsi, dans «l'élaboration d'une légitimité », Natalie Petiteau souligne combien la mémoire impériale a pu inspirer les rêves républicains de l'homme providentiel et de la "grande nation ». À propos de « la fabrication des normes », Nicolas Delalande s'attarde sur la rhétorique de l'impôt comme outil de civisme républicain et instrument de justice sociale. Quant aux "processus de républicanisation ", la course aux honneurs et aux faveurs mérite une attention particulière. Frédéric Caille et Frédéric Monier rappellent chacun que la Troisième République n'a jamais rompu avec les traditionnelles techniques de gouvernement que sont les usages symboliques des décorations et le recours aux clientèles électorales.

4 Au bout du compte, l'histoire de cette Troisième République apparaît convaincante. Certes, on pourra regretter certaines impasses comme «Le cléricalisme, voilà l'ennemi » au sein des « idées reçues » ou «La République des communes » parmi les autres « boîtes noires » possibles ${ }^{3}$. Reste que l'originalité de cet ouvrage porte non plus sur un modèle qui serait intangible pour les autres Républiques mais sur un projet « qui n'est pas défini une fois pour toutes" (p.8). Ainsi, demeure-t-il ouvert aux changements et aux mutations de la société française. Inversement, il ne doit plus être sanctuarisé comme un objet de culte et de vénération, ne permettant plus à la République d'évoluer et d'épouser son temps. Si la Troisième République a pu être considérée comme un "modèle", plus à usage historiographique que politique, sa relecture aujourd'hui comme "projet républicain " possède donc une réelle valeur heuristique. Cependant, s'agit-il ici d'une "contre-histoire»? Le terme nous semble davantage une opération éditoriale qu'historiographique. L'ouvrage n'a rien d'un « livre noir » ou d'une entreprise de dénégation. Il trace tout simplement les chemins pour une «autre histoire » de la Troisième République. Et c'est en cela qu'il est une réussite. 


\section{NOTES}

1. De La République au village (1970) à La République de 1880 à nos jours (1990) en passant par les Marianne au combat (1979) et au pouvoir (1989).

2. Serge Berstein et Odile Rudelle [dir.], Le modèle républicain, Paris, Presses universitaires de France, 1992.

3. Jacqueline Lalouette, La République anticléricale (XIX $-X X^{e}$ siècles), Paris, Le Seuil, 2002 ; Louis Fougère, Jean-Pierre Machelon et François Monnier [dir.], Les communes et le pouvoir. Histoire politique des communes françaises de 1789 à nos jours, Paris, Presses universitaires de France, 2002. 